\title{
Multivariate Contagion and Interdependence
}

\author{
Dirk G. Baur ${ }^{1^{*}}$ \\ $\&$ \\ Renée A. Fry ${ }^{2^{*}}$
}

March 2009

\begin{abstract}
This paper proposes a multivariate test to measure the statistical and economic significance of contagion through analysis of extreme unobserved common shocks. Contagious episodes are endogenously determined with no need, but the possibility, to specify the source country. Application to a panel of equity returns during the Asian crisis of 1997-98 finds that interdependencies are substantially more important than contagion. However, the periods of contagion evident show that it is short-lived, split between positive and negative movements and reverses quickly. In comparison to other Asian crisis countries, Hong Kong was the main driver of contagion in the Asian crisis. The proposed methodology and the empirical findings provide a more detailed picture of contagion than commonly applied tests.
\end{abstract}

\section{JEL classification: C10, C51, F36, G14, G15}

Keywords: contagion, interdependence, common movements, panel data, fixed time effects, Asian crisis, equity markets, endogenous crisis period, asymmetries

\footnotetext{
${ }^{1}$ Corresponding author. Address: Dublin City University - The Business School, Glasnevin, Dublin 9, Ireland. Email: dirk.baur@dcu.ie

${ }^{2}$ Address: Centre for Applied Macroeconomic Analysis (CAMA), College of Business and Economics, the Australian National University, Canberra, Australia, and the Cambridge Endowment for Research in Finance, University of Cambridge. Email: renee.fry@anu.edu.au

*We would like to thank an anonymous referee, conference participants at the Econometric Society World Congress, 2005, the Australian Conference of Economists, 2006, Niels Schulze and Mardi Dungey for useful comments. Fry gratefully acknowledges funding from ARC grant DP0343418.
} 


\section{Introduction}

The incidence of financial crises over the past decade has ignited research into the nature of the spread of financial crises across borders, with the conduit of 'contagion' an important focus. Contagion can be defined as an increase of common movements in a set of financial asset markets in a particular period of time (a crisis period) compared to those existing in a benchmark (non-crisis) period (Baig and Goldfajn, 1999 and Forbes and Rigobon, 2002). ${ }^{1}$ Methodologies developed to model contagion emphasize that normal (non-crisis) interdependencies and common factors between markets need to be accounted for before the spread of crises through contagious channels can be determined (Bae, Karolyi and Stulz, 2003 and Bekaert, Harvey and Ng, 2005). Comovements during a non-crisis period reflect economic and financial interdependencies, such as trade linkages, systematic capital flows and banking linkages. Contagion, on the other hand, is the component that is unexplained and unexpected. This view is equivalent to others prevalent in the literature on financial market crises, including that of Masson (1999) where interdependencies equate to his monsoonal and spillover effects with the residual being contagion; Calvo and Reinhart (1996) and Kaminsky and Reinhart (2000) where there is a distinction between 'fundamentals' based contagion (interdependencies) and 'pure' contagion; and Mody and Taylor (2007) where common vulnerabilities represent interdependencies and contagion is linkages that are unexpected.

This paper contributes to the literature on contagion testing by proposing a multivariate test based on the cross-sectional and time-series dimension of the data that controls for interdependencies and systematic risk through regional and global equity market indices, and where contagion is analysed through the significance of fixed time effects. The fixed time effects are estimates of the time-varying joint movements in asset markets not explained by the regional or global factors during a crisis period. If on any date during a crisis period a fixed time effect reaches a certain threshold, there is evidence of a large unexplained common factor that is interpreted as contagion.

\footnotetext{
${ }^{1}$ A critique of definitions of contagion are provided by both Pericoli and Sbracia (2003) and the World Bank (http://www1.worldbank.org/contagion/definitions.html).
} 
Theoretical models often explain contagion through the appearance of an additional factor common to a set of countries, mainly through the role of investors in the global economy. These include models based on herding behaviour, information asymmetries or cascades (Calvo and Mendoza, 2000, and Yuan, 2005), portfolio re-balancing (Kodres and Pritsker, 2002), wealth constraints (Kyle and Xiong, 2001 and Yuan, 2005) and borrowing constraints (Boyer, Kumagai and Yuan, 2006). ${ }^{2}$ Although it is difficult to evaluate empirically the concepts these papers suggest, they all have in common that asset markets that appear not related develop an additional linkage arising through circumstances in the international financial environment. The fixed time effect focus of this paper captures this additional factor affecting all asset markets.

The paper uses a panel of daily returns of Asian equity markets with a focus on the Asian financial crisis of 1997 - 1998 to demonstrate the application of the model. Most empirical models of contagion are estimated using daily, rather than lower frequency data such as weekly data, in order to capture the frenetic nature of events during crises. As the fixed time effects enter into all (eleven in this application) asset markets in the period surrounding the crisis, their significance is likely to reflect genuine periods of contagion, as it is improbable that a diverse group of countries all develop additional significant linkages above normal interdependencies on any particular day.

In modelling contagion and crises, panel data techniques are not widely used. Fratzscher (1999, 2003) uses a random effects panel model to examine contagion in currency markets, while numerous other papers draw on the exchange pressure index methodology of Eichengreen, Rose and Wypolz $(1995,1996)$, also for currency markets (see also Van Rijckeghem and Weder, 2003 and Calvo and Reinhart, 1996). Alternative multivariate approaches include those based on vector autoregressions (Favero and Giavazzi, 2002); coexceedances (Bae, Karolyi and Stultz, 2003 and Baur and Schulze, 2005); observed and latent factors (Dungey and Martin, 2004, Corsetti, Pericoli and Sbracia, 2001, 2005 and Bekaert, Harvey and Ng, 2005); and changes in the determinant of covariance matrices (Rigobon, 2003).

\footnotetext{
${ }^{2}$ Developments in the theoretical literature in response to the subprime crisis also include linkages through institutions known as network effects. See Allen and Babus (2008) and Gai and Kapadia (2008) for examples. This work is related very much to the pioneering work of Jackson and Rogers (2007).
} 
While being relatively simple to implement, modelling contagion through fixed time effects presents several advantages that overcome many restrictive elements of current tests of contagion. Most important is the extraction of a relatively long time-series measuring contagion. This alleviates sample selection bias arising through the choice of the sample period (Pesaran and Pick, 2007), as the model is not explicitly identified through the ex post definition of a crisis period. Statistically and economically, the importance of contagion is assessed on a daily basis. This means that contagion is endogenously determined as the fixed time effects duration can extend to a multiple of the actual crisis period length, and is not constrained to be a feature of the crisis sample period. The only other paper that we are aware of that presents a time series effectively capturing such linkages in a crisis period is Diebold and Yilmaz (2008). In the same way as the method proposed here, their spillover index is able to capture crisis linkages and is not constrained to represent an average over a crisis period as most models measuring crisis transmissions are. The proposed method, and Diebold and Yilmaz (2008), both also avoid the difficulty of specifying a crisis trigger country. This is advantageous in cases such as the Asian financial crisis where there is no clear trigger country or asset market. However, the evaluation of hypotheses regarding the source of contagion can be evaluated in our framework.

Distinguishing between negative and positive contagion is an additional advantage of the approach here. Theoretically, positive contagion may arise because of the some of the same theoretical reasons that negative contagion may arise, such as herd behaviour (see also Bayoumi et al., 2008). The distance based correlation estimator of Bayoumi, Fazio, Kumar and MacDonald (2008) is also able to determine the importance of 'positive' contagion. Further advantages of the method include that asymmetries due to contagion can be assessed, and the daily nature of the time series of contagion means that key events of the crisis period can be analyzed to gain some indication of whether these events tend to be associated with contagion.

The remainder of the paper is organized as follows: Section 1 presents the econometric framework used to estimate systematic risks and contagion, followed by a description of the data set and the specification of the fixed time effects in Section 2. Section 3 provides the 
estimation results. The results indicate that overall there is little evidence of contagion and that equity market returns are mainly determined by interdependencies. However, there are four main periods in which contagion is significant, and the breakdown of these instances are roughly split equally between negative and positive episodes. Matching these periods with news or events suggests that contagion in the Asian crisis was mainly associated with events in Hong Kong. A discussion of controlling for fundamentals is contained in Section 4. Section 5 concludes.

\section{The Econometric Framework}

This section proposes a panel data model with fixed time effects to analyze contagion across a set of $N$ asset markets. The framework is a regression model of the form

$$
y_{i, t}=\alpha_{i}+\gamma_{t^{*}}+\beta_{i 1} f_{\text {regional }, t}+\beta_{i 2} f_{\text {global }, t}+\varepsilon_{i, t}
$$

where $y_{i, t}$ is the return of country $i$ at time $t$. The model contains a constant $\alpha_{i}$ for each return vector $y_{i}$, and $f_{\text {regional, } t}$ and $f_{\text {global, },}$ are regional and global factors, respectively. The regional and global factors control for interdependence with corresponding loadings $\beta_{i 1}$ and $\beta_{i 2}$ and it is assumed that the regional and global equity market factors adequately price economic and financial market risks. The choice of regional and global factors for the empirical example is discussed in Section 2.

The parameter $\gamma_{t^{*}}$ represents a fixed time effect which is defined for a period of $K$ units of time (for example, days) across all countries. The fixed time effects are interpreted in comparison to a base period and represent contagion in the model. They capture time-varying joint positive or negative movements across all asset markets that are not explained by the regional or global factors. Intuitively, contagion is problematic when all markets simultaneously plummet, but a simultaneous rise in all markets above that implied by interdependencies may also constitute contagion. ${ }^{3}$ In commonly used frameworks, positive and negative contagion is neither distinguished nor discussed. The implications of this are

\footnotetext{
${ }^{3}$ The fixed time effect could also be defined to enter $\mathrm{M}<\mathrm{N}$ markets to enable contagion to occur in a subset of markets. This would enable comparison of the results here with models with a bivariate structure for example. This is not pursued here as in the first instance it is assumed that contagion is in the most extreme form as alluded to by the theoretical models of Boyer et al. (2006) and Yuan (2005), affecting all asset markets in the sample.
} 
important for the analysis of contagion, as the economic significance of contagion is different vis-à-vis positive versus negative contagion.

The error terms in (1) is given by $\varepsilon_{i, t}$ and are assumed to exhibit conditional autoregressive heteroscedasticity modelled via a GARCH process. There are two options in specifying the GARCH process. First, conditional heteroscedasticity may be modelled as a pooled average with the same GARCH parameters for all markets. ${ }^{4}$ Second, the model may be estimated in two stages. In this case, a univariate GARCH process is specified separately for each country in the first stage, with the resulting residuals regressed on the fixed time effects. The second option is the preferred choice and is adopted here because of its flexibility. The model is estimated using Maximum Likelihood.

The window of the fixed time effects (1) is defined over a period spanning from $t=0$ until $t=0+K$ with $t^{*}$ denoting this interval. This potential crisis period may span the total sample period or may be restricted to a sub-sample for economic reasons or efficiency issues regarding the standard errors of the parameter estimates. If the fixed time effects reach a certain threshold, there is evidence of a large unexplained common factor interpreted as joint contagion. The threshold chosen in this application is based on conventional significance levels. If on any day an estimate of an element of $\gamma_{t^{*}}$ is significant at the 99 percent level of significance, there is evidence of joint contagion. ${ }^{5}$ The use of the 99 percent level of significance is consistent with alternative methods of analysing contagion. See Dungey, Fry, González-Hermosillo and Martin (2005) for a review of contagion models and a discussion of the thresholds typically used. The significance of contagion is assessed statistically on a daily basis. Choosing the duration of the fixed time effect so that it entirely encompasses the crisis period or a set of potential crises periods means that the exact dates on which contagion is important are determined by the data itself.

\footnotetext{
${ }^{4}$ For example, $h_{t}=a+b \varepsilon_{t-1}^{* 2}+c h_{t-1}$ where $h$ is the conditional variance based on the cross-sectional mean of the residuals $\varepsilon^{*}$ at $t-1$.

${ }^{5}$ Since maximum likelihood estimation is employed the appropriate statistic is the z-statistic (Greene, 2003).
} 
The use of the fixed time effect in measuring contagion relates to other models of contagion using thresholds in various ways (see Dungey et al., 2005 for a discussion of how models of contagion relate to each other in general). For example, the Favero and Giavazzi (2002) model of contagion (applied to the ERM crisis in Europe) estimates a VAR of the asset returns contained in a vector $y_{t}$ and obtains the residuals, $e_{t}$

$$
e_{t}=y_{t}-\phi y_{t-1} .
$$

Dummy variables corresponding to values exceeding a threshold are defined for each asset as

$$
d_{i, t}=\left\{\begin{array}{lc}
1: & \left|e_{i, t}\right|>\text { threshold } \\
0: & \text { otherwise }
\end{array},\right.
$$

where the threshold is $3 \sigma_{i}$, where $\sigma_{i}$ is the standard deviation of the residuals of each equation. An additional dummy variable $d_{c, t}$ is defined to account for common shocks occurring on a particular day where for a trivariate case,

$$
d_{c, t}=\left\{\begin{array}{cc}
1: & d_{1, t}=1 ; d_{2, t}=1 ; d_{3, t}=1 ; \\
1 & d_{1, t}=1 ; d_{2, t}=1 ; d_{3, t}=0 ; \\
1 & d_{1, t}=1 ; d_{2, t}=0 ; d_{3, t}=1 ; \\
1 & d_{1, t}=0 ; d_{2, t}=1 ; d_{3, t}=1 ; \\
0: & \text { otherwise }
\end{array}\right.
$$

The dummy variables $d_{i, t}$ are adjusted to remove the common impulses. The $d_{i, t}$ and $d_{c, t}$ variables then enter into a structural equation for each asset return, with the significance of the cross asset market dummies representing contagion. The first line of the $d_{c, t}$ variable in (2) would be equivalent to the $\gamma_{t^{*}}$ here if an individual common dummy variable $d_{c, j, t}$ was constructed for each of the $j=1,2, \ldots J$ cases of $d_{1, t}=1 ; d_{2, t}=1 ; d_{3, t}=1$.

Bae et al. (2003) and Boyson, Stahel and Stulz (2008) also focus on the joint occurrence of asset returns being in the tails of a distribution. Effectively they consider the significance of each line of (2) in individual dummy variables as their measure of contagion. Their joint extremes are labelled coexceedances. The significance of contagion is assessed in a multinominal logit model. However, the parameters on the coexceedances are not allowed to 
vary over time, meaning that the economic importance of contagion is constrained to be equal across a specific (crisis) period.

In comparison to the bivariate Forbes and Rigobon (2002) test, the change in the correlation coefficient across a non crisis and crisis period is implemented first by controlling for market fundamentals through a VAR (with the inclusion of the US interest rate $\left(r u s_{t}\right)$ as an additional control). The test for contagion is then conducted by obtaining the residuals $\left(e_{t}\right)$

$$
e_{t}=y_{t}-\phi y_{t-1}-\beta r u s_{t},
$$

and defining the non crisis data $\left(z_{t}\right)$ as the total sample period $\left(z_{t}=e_{t}\right)$ and the crisis period data as $\left(x_{t}\right)$, with $T_{x}$ and $T_{z}$ observations respectively. The crisis period is specified exogenously. The FR test is formally

$$
F R=\frac{\frac{1}{2} \ln \left(\frac{1+\hat{v}_{x}}{1-\hat{v}_{x}}\right)-\frac{1}{2} \ln \left(\frac{1+\hat{\rho}_{z}}{1-\hat{\rho}_{z}}\right)}{\sqrt{\frac{1}{T_{x}-3}+\frac{1}{T_{z}-3}}},
$$

where $\hat{v}_{x}$ is an adjusted correlation coefficient of the asset returns in the crisis period, and $\hat{\rho}_{z}$ is the correlation coefficient in total sample period. Evidence of contagion is found if the difference between the two tests is significant. It is clear that this test for contagion is a joint test for contagion over the entire crisis period, it is not feasible to assess contagion on a daily basis using this model, and it is also not possible to determine if contagion is negative or positive, or if this in fact changes through the crisis period. 


\section{The Data and Fixed Time Effect}

The data set consists of daily (close-to-close) continuously compounded stock return indices $\left(y_{i, t}\right)$ of eleven Asian stock markets: China, Hong Kong, India, Indonesia, Japan, Korea, Malaysia, the Philippines, Singapore, Taiwan and Thailand. ${ }^{6}$ Interdependence arising from both regional $\left(f_{\text {regional }, t}\right)$ and world $\left(f_{\text {global }, t}\right)$ factors is controlled for in the model through the inclusion of the returns of the MSCI World and the MSCI Emerging Markets Free (EMF) Asia indices, respectively. ${ }^{7}$ All index returns are denominated in US dollars and span a time-period of about 7 years from April 30, 1997 until October 22, 2003. This is a sample of 1690 observations for each country. The US dollar denomination is chosen to evaluate contagion from the perspective of the international investor since currency appreciations or devaluations are implicitly incorporated in the model.

Most of the countries in the sample are directly involved in the Asian financial crisis, including Thailand and Hong Kong. Thailand's devaluation of the baht and subsequent depreciation in July 1997, and Hong Kong's speculative attack in October of the same year are considered key crisis events. Indonesia, Korea and Malaysia are also crucial crisis countries, while the peg of the Taiwanese dollar was broken just prior to the Hong Kong speculative attack. The Philippines also experienced large devaluations. China is included in the sample as it is a large economy in the region and after the handover of Hong Kong to China in 1997 was presumably important to Hong Kong in terms of investor expectations of the level of reserves accessible to fend off a speculative attack. Japan and Singapore are included in the sample as they are large financial centres in Asia, and India is particularly interesting for the analysis of contagion since its financial markets are rather isolated. The inclusion of India is important in capturing system wide contagion. ${ }^{8}$

\footnotetext{
${ }^{6}$ The countries selected have non-synchronous trading hours which may cause some empirical problems as documented in Lo and MacKinlay (1990). However, as the countries are from one region, it is considered to be a minor issue.

7 The data is provided by Morgan Stanley Capital International Inc. (MSCI) and can be retrieved under www.mscidata.com.

${ }^{8}$ As noted earlier, a less stringent view of contagion could be imposed by defining the fixed time effect to enter into a smaller subset of countries.
} 
The fixed time effects $\left(\gamma_{t^{*}}\right)$ extend from May 2, 1997 to May 29, 1998, a total of 281 observations. The selection of these dates captures the Asian financial crisis with additional observations on either side. These dates encompass most (if not all) others in the literature (see for example Baig and Goldfajn, 1999, Forbes and Rigobon, 2002, and Bekaert, Harvey and Ng, 2005). The end date is chosen to end before the build up of pressure in global financial markets prior to the Russian crisis of August 1998. Dating the end of a crisis is usually problematic while the beginning is marked by an extreme event, although the beginning of the Asian crisis is not entirely agreed upon. Forbes and Rigobon (2002) motivate the period surrounding the Hong Kong crash as their crisis period, as it was not until this time that media outside of Asia devoted attention to the crisis (see also Corsetti et al., 2005 and Dungey, Fry and Martin, 2003). The Forbes and Rigobon (2002) crisis dating extends from October 17, 1997 to November 16, 1997. Others including Baig and Goldfajn (1999) use the baht devaluation as the beginning of the crisis. Using fixed time effects avoids the problem of a priori defining the crisis window, as the fixed time effect is not constrained to represent contagion on every date inclusive in the crisis period. Robustness to the duration of the fixed time effects is presented in Section 4.

Figures 1 and 2 present the equity price and return indices for each of the eleven countries over the total sample period, respectively. Table 1 reports the corresponding descriptive statistics of the returns. The important points to note from the figures and table are that the markets simultaneously fall in the second half of 1997 and that volatility is greater in the period surrounding the crisis (the fixed time effects period) compared to the rest of the sample period with the exceptions of Taiwan and India. Table 2 presents unconditional correlation coefficients calculated over the total sample period (upper diagonal) and the fixed time effects period (lower diagonal). All correlation coefficients are positive, and are generally higher during the fixed time effects period than in the total sample period. These correlation coefficients are provided for information only and do not necessarily indicate evidence of contagion, as there is no correction for heteroscedasticity (Forbes and Rigobon, 2002), and correlation based measures of contagion are not necessarily adequate to capture contagion (Rigobon, 2003). 


\section{Empirical Results}

This section presents the results for the estimation of the model specified in equation 1 , with all calculations are performed in Stata version 9. The parameter estimates and z-statistics of the loadings on the variables capturing interdependence, namely the regional $\left(\beta_{i 1}\right)$ and global factors $\left(\beta_{i 2}\right)$, are presented in Table 3. Table 3 shows that the regional risks are important for all countries in the sample. Bae et al. (2003) also find regional variables important in explaining asset movements, supporting these results. The coefficients on the regional factor $\left(\beta_{i 1}\right)$ range from between 0.34 for Japan, to 1.48 for Korea. Global risks are important for all of the developed countries (Hong Kong, Japan and Singapore) and two of the emerging countries, namely China and Malaysia. The sign of the parameters on the global factor for Malaysia and Taiwan are negative which contrasts with all other countries in the sample.

Estimates of the fixed time effects and their corresponding z-statistics are shown graphically in Figure 3. Inspection of panel a) of the figure indicates evidence of joint contagion across the eleven countries for the equity returns in four episodes as measured by their significance at the 99 percent level. Altogether, there is evidence of system wide contagion on 28 dates.. This represents about ten percent of all observations in the fixed time effects window. ${ }^{9}$ On the remaining approximately 90 percent of days, equity market prices are determined by global and regional systematic risks. Interdependence through regional and global relationships remains the dominant reason for co-movements in the equity markets.

This result is qualified by noting that the form of contagion testing in this paper is more stringent than other definitions of contagion in that every country is affected by construction. Others such as Corsetti et al. (2005), Forbes and Rigobon (2002), Bekaert et al. (2005), and Bae et al. (2003) find that contagion is limited to a subset of countries. However, the focus of these papers is on capturing contagious linkages between subsets of countries, rather than taking a system-wide view as in this paper. Although this raises the possibility of that the method of contagion identification is susceptible to sample selection bias in terms of choice of

\footnotetext{
${ }^{9}$ As noted earlier most contagion studies do not present a time series of contagion, or do not identify contagion attributable on a particular date. The exception is Diebold and Yilmaz (2008), however, the dates of contagion are not detailed in their paper, inhibiting comparison.
} 
countries in the sample, the choice of countries is wider than in most empirical applications. Further, most other studies focussing on cross regional contagion find no linkages during the Asian crisis (Bekaert, Harvey and Ng, 2005 and Wongswan, 2003).

When contagion exists, the parameter estimates of the fixed time effects are generally large in absolute terms, and tend to cluster. The episodes of contagion correspond to four main periods: (i) September 2 to September 4, 1997, (ii) October 24 to October 30, 1997; (iii) December 12, 15 and 23, 1997 and (iv) January 8 to January 28, 1998 along with several dates in February, March and May of 1998 which are less clustered. Column 2 in Table 4 contains the dates on which contagion occurs for the model in equation (1).

On the days that there is contagion, it is clear that contagion is not just a negative event. Just over one third of all instances of contagion are positive (10 days), compared to 18 days of negative contagion (18 days). In their analysis based on coexceedences, Bae et al. (2003) find symmetry in the number of occurrences of joint negative asset market movements and joint positive asset market movements for the Asian crisis period. Some of the days of positive contagion are quite large in terms of absolute value. This is an important finding with implications for investor diversification and optimal portfolio allocation, as portfolio diversification decisions are made based on measures of the strength of the common movement of asset prices. This strength is often measured with the correlation coefficient, which is not able to distinguish between co-movements that are governed by joint positive or joint negative shocks. Portfolio diversification opportunities change with the appearance of significant fixed time effects.

There are calm periods within the window of the fixed time effect where there no contagion is detected. For example, the first 80 observations (May to September, 1997). This demonstrates the biggest advantage of the model where the crisis period encompasses non crisis observations to no detriment. To further establish that this is actually the case a period where there is no crisis in the Asian region is examined. A visually “calmer” period can be identified from January 2001, and a window of the same length as the original window (281 observations) is defined until February 2002. For this period, two occurrences of contagion at the $1 \%$ level of significance are detected, indicating that the proportion of contagion is much lower than then $10 \%$ of observations found during the Asian crisis period, with 
around $0.7 \%$ of observations being defined as contagion in the later window. Further moving the window by 281 observations towards the future yields one occurrence of contagion at the $1 \%$ level of significance.

As the fixed time effect is a daily time series of the period surrounding the crisis, it can provide evidence on the extent of asymmetries in equity returns during the crisis. Ang and Chen (2002) and Butler and Joaquin (2002) provide evidence on this effect. Ang and Chen (2002) for example find evidence of asymmetries in the form of downside correlations being greater for US stocks with the overall market than on the upside, and Butler, Kumagai and Yuan (2006) find that wealth constraints can lead to asymmetric correlations with correlations higher during market downturns.

Although not based on correlations but on the values of the fixed time effects that enter all markets, Table 5 provides some simple calculations to determine whether asymmetries exist. The first two columns of data show the mean value of the fixed time effect for all observations, all positive observations, and all negative observations, along with the corresponding sample size in each case. Overall, the mean value of the fixed time effect is -0.11 percent. The mean of the fixed time effect for the positive observations is 0.67 percent, which is lower in absolute magnitude than for the negative observations (-0.74 percent). Although this provides evidence of asymmetries, whereby the magnitude of the fixed time effect on the downside is larger than upside, performing similar calculations only on the days on which there is evidence of contagion presents a different case. On days of contagion, the mean value of the fixed time effect for the positive observations is 2.60 percent. This magnitude is greater than that for the negative observations of -2.36 percent. However, the total effect of contagion is still negative as given by the mean of $-0.17 \%$.

The results presented here indicate that contagion is relatively rare, and that the variables measuring interdependencies are significant. The interpretation borrowed and consistent with Forbes and Rigobon applies, that is, there is no (or little) contagion, but only interdependence. Despite this result, it is still useful to attempt to understand the reasons behind the four episodes of contagion that do exist. The following summarises the events occurring during the 
four periods that exhibit the most pronounced contagious effects to glean some indication as to possible reasons for the contagion that does exist. For a more detailed chronology see Baur and Fry (2006) and references therein.

\section{Episode 1: September 2 to September 4, 1997}

The key item of news to hit financial markets in the first period of contagion corresponding to September 2 to 4 in 1997 was the announcement on the previous day that the Malaysian Government had imposed restrictions on forward sales of the ringgit and banned short-selling in equity markets (Kaminsky and Schmukler, 1999, and Athukorala, 2001). The fixed time effect on September 4 is positive, compared to the negative value on September 2. The similarity of the absolute magnitudes (3.19 versus 3.94 ) of these contagious events suggests a market correction.

\section{Episode 2: October 24 to 30, 1997}

The second period of contagion overlaps the period of the Hong Kong speculative attack and equity market crash of October 1997 and the following US equity market crash where the Dow Jones lost over 7 percent of its value in one day (see BBC 1998 and the Washington Post, 1998). The Hong Kong speculative attack began on October 20 and lasted for just over a week, with most of the impact felt on October 20 to 23. This event is considered to be one of the most important of the Asian crisis. The fixed effects are not significant for every day of the period of the attack, but are significant on October 4, 29 and 30, as is clearly demonstrated in Figure 3. The parameters are negative on October 24 and 29, but there is evidence of positive contagion on October 30, potentially indicating the end of the speculative attack and a reversal in market sentiment. The negative contagion effect on October 29 reflects the response (given the time difference between New York and Asia) of the Asian markets to the US falls. Several countries were also downgraded or put on review for downgrade by Moody's and Standard and Poors during the turbulent Hong Kong crash period. Diebold and Yilmaz (2008) find that their spillover index jumps sharply during this period. 


\section{Episode 3: December 12, 15 and 23, 1997}

The third period of contagion that occurs between December 12 and 23, 1997 corresponds to issues affecting Korea at this time. An internal IMF document leaked on December 10 stated that two banks would close, foreign exchange reserves had rapidly depleted, and short term debt was almost double that suggested in government statements (Ito, 2007). On December 11 and 12, trading of the Korean Won was halted in reaction to the news of the previous days, and equity markets fell markedly during this time. On December 22, the sovereign debt ratings of Indonesia, Malaysia and Korea were downgraded by Moody's investor service. Over the course of 1997 this represented a downgrade from an investment grade rating to junk status for Korea.

\section{Episode 4: January to May, 1998}

The fourth period of contagion in early 1998 is the longest in duration and the most extreme in terms of magnitude of the parameter estimates. There was substantial financial, economic and political turmoil in many countries throughout the region over this time, and there are clear instances of both negative and positive contagion effects reflecting the intensity of the uncertainty of this period. In the month of January, there are several instances of both positive and negative contagion.

Negative contagion on January 8 and 9 coincides with turmoil in Indonesian financial markets; reports hit the market that the IMF was unhappy with Indonesia's commitment to reform. Equity markets fell by up to 19 percent over the day, and the Rupiah per US dollar exchange rate broke 10,000. Indonesia was in the midst of its crisis in January, with political uncertainty surrounding the forthcoming presidential elections. Further, Korea, who had successfully negotiated with foreign banks to roll over their short term debt in the previous December, was negotiating the rollover of the US dollar 20 billion in short term debt due later that month (Ito, 2007), although Korea was also the beneficiary of 2 billion dollars from the IMF earlier in the month. Thailand and Indonesia were downgraded by rating agencies, and several other countries were due to have their ratings announced in the subsequent days. The significant fixed time effects of January 13, to 16, 20, 23 and 27, 1998, appear driven by market sentiment. The collapse of Hong Kong based Peregrine Investments of January 13 coincided 
with negative contagion, with a fixed time effect value of -0.017 . This was reversed on January 14 with a value of 0.029 .

In the final period of contagion between February and May, events in Korea and Indonesia were largely in the headlines. Korea successfully negotiated the roll over of a series of shortterm debt contracts into longer-term instruments, which in turn strengthened the Korean banking sector (Ito, 2007). However, there does not seem to be a correspondence with particular events and contagion in the later part of the sample.

\section{The Role of Hong Kong, Indonesia and Korea}

In matching contagion with anecdotal news events, no pattern potentially causing contagion emerges, although Hong Kong, Indonesia and Korea (three of the key crisis countries) seemed to be prominently in the headlines corresponding to days on which contagion is important. To examine the role of these countries in explaining contagion, the model is re-estimated with either of Hong Kong, Indonesia or Korea included in the vector of exogenous variables, and the corresponding return dropped as an endogenous variable. The results are shown in Figure 4 and columns 4 to 6 of Table 4. Controlling for Hong Kong eliminates the periods of contagion prior to December 1997 and reduces the magnitude of the later episodes. This result confirms the importance of the Hong Kong speculative attack in contributing to asset market volatility during the period. Performing similar experiments with the Korean and Indonesian and Thai returns does not eliminate contagion to the extent of Hong Kong, with Indonesia accounting for more contagion than Korea. ${ }^{10}$

\section{Controlling for Fundamentals}

The detection of contagion depends on the adequate specification of the interdependencies and market fundamentals. The choice of fundamentals is dictated by views on the nature of the crisis and the frequency of data appropriate for the choice of modelling contagion. Most studies of contagion view daily data as most relevant, as a crisis period is usually characterized by high volatility which is often short lived. To ensure that this remains the case here, the model was

\footnotetext{
${ }^{10}$ A similar experiment was performed for Thailand which is often associated with the beginning of the crisis, with little change to the incidence of contagion.
} 
estimated using returns data based on a two day time frame, yielding evidence of contagion on only one day across the period over which the fixed time effect is defined. The use of lower frequency data can dilute the frantic nature of the crisis, making analysis of contagion difficult. The challenge is then to determine appropriate fundamentals available on a daily basis. The choice in this paper is the regional and global equity indices.

Alternative methods of controlling for fundamentals include Forbes and Rigobon (2002) and subsequent papers following their methodology which estimate a vector autoregression (VAR) model with 5 lags of the sample asset markets along with the US interest rate to control for global factors. Chiang, Jeon and $\mathrm{Li}$ (2007) use the lagged equity returns of all markets along with the US equity returns. Baig and Goldfajn (1999) present two approaches. The first controls for fundamentals using a $\operatorname{VAR}(1)$, and the second defines a dummy variable constructed from press reports which proxy movements of fundamentals which is used in conjunction with the S\&P500, and the Yen-dollar exchange rate. Dungey, Fry and Martin (2003), Caporale, Cipollini and Spagnolo (2005) and Corsetti, Pericoli, Sbracia (2005) use latent factor models to control for common factors, again using data of daily frequency. Bekaert, Harvey and Ng (2003) also construct a latent factor model, but they also condition on observed fundamentals such as local dividend yields, trade ratios with the US, trade ratios with the region and trade ratios with the world, but they are able to do this because they use monthly rather than daily data. All of these papers focus on the Asian crisis.

The model of this paper has in common with the factor models that world and regional factors are specified in both genrés of models, with the fundamentals of the factor models being latent, and the one in this paper proxied by the regional and global equity indices. To evaluate the robustness of this choice and to further enable comparison with some of the papers listed above, the model in (1) is respecified with the analysis conducted on the residuals of a VAR(5) to control for interdependencies. The regional and world equity indices are dropped from the specification of the model.

The results in the first panel of Figure 5 show that there is more evidence of contagion when fundamentals are proxied with the VAR, with 47 days on which contagion is important. This 
suggests that in the returns data interdependencies based on contemporaneous relationships are important. Comparison of this model with the results of Forbes and Rigobon where there is little evidence of contagion suggests that perhaps the correlation based method of detection of contagion where contagion is a feature of the entire crisis period has the effect of diluting the contagion that is actually there.

As a further robustness check as to the sensitivity of the model to the variables measuring regional and global systematic risks, two further model specifications are considered. ${ }^{11}$ First, the condition $\beta_{i 1}=0$ is imposed so that interdependence is accounted for only by the global factor. The parameter estimates of the fixed time effects correspond with the extremes in the model in equation (1), along with an additional 48 instances of contagion. These results are shown in the second panel of Figure 5. The values of $\beta_{i 2}$ markedly increase, with many estimates more than quadrupling (not shown). In the case of only allowing for interdependencies through the regional factor, obtained by setting $\beta_{i 2}=0$ (third panel in Figure 5), contagion again occurs on 28 dates and these correspond to those of the model in equation (1). This result indicates that controlling for regional interdependencies is potentially more important than controlling for global interdependencies. What appears to be contagion in models not controlling for regional interdependencies may in fact be an artefact of this omission. The significance of the regional factor compared to the global factor in Table 3 confirms this result.

The application to illustrate the implementation of the test of contagion based on the fixed time effect is broad in nature in that it contains a wide variety of economies from the region. About half of the sample was directly involved in the crisis, with the other half less so. This choice of an encompassing sample is able to provide an indication as to the extent of the systemic nature of contagion during the crisis period. The inclusion of a large sample is informative in understanding how and if isolation of financial markets (India and to some extent China),

\footnotetext{
${ }^{11}$ Additional sensitivity analysis was conducted on the specification of the disturbance term, the effect of asymmetries in the variance specification, the duration of the fixed time effect, the impact of time varying interdependence, and the specification of a fixed interdependence model where the parameters on the global and regional factors are constrained to be equal across the panel of countries. These results are available from the authors on request.
} 
fundamentally sound countries (China and Japan), and countries of varying levels of development and openness (China (Cordon, 2002), India and Japan) affects the transmission of a crisis. Policy responses during a crisis can be informed by this type of analysis. To examine the sensitivity of the results to the choice of sample, the model specification in (1) is altered by removing China, India and Japan and reestimating the model in (1).

Include paragraph on the interdependencies and regional factors.

The results of this experiment are included in the last column of Table 4, and in the last panel of Figure 5. In this version of the model there are 38 dates on which contagion is important. The omission of China, India and Japan generate more contagion compared to the larger sample, with 11 additional dates on which contagion is important for a total of 34 dates. 23 of the 28 days of contagion of the full model correspond. The insight from this analysis is that when contagion is at it's purest during episode 4 described in Section 3 where it is most difficult to attribute the existence of contagion to particular events, there is barely any difference between the two models in terms of detecting contagion. This is shown clearly by comparing column 1 and column 5 of Table 4 for the months of January and February in 1998. It appears that contagion during this time period is truly systemic in the Asian region across this period with a very strong correspondence between the two samples. It appears that during a period of extreme crisis (for example, during episode 4), none of the factors of isolation of financial markets, level of development or openness or sound fundamentals matter.

The differences in the results in terms of their being additional days on which contagion is important compared to the model are as expected, as the fixed time effect is a function of the underlying data. The underlying data is more volatile and extreme without the influence of China, India and Japan compared to the smaller sample. Inspecition of Table 1 clarifies that the extremes (the minimum and maximum values of the returns) are relatively smaller for the three omitted countries compared to the remainder of the countries. Hence, if these countries are included in the estimation, the frequency and the severity of contagious shocks is reduced.

\section{Concluding Remarks}


This paper presented a new test for contagion applied to the equity returns of eleven countries during the Asian financial crisis of 1997-1998. In line with current contagion tests, the methodology controlled for interdependencies arising through relationships with nearby countries, as well as from global financial markets. The modelling of contagion proceeded through the significance of a fixed time effect series that entered into the asset return equation of every country. System-wide contagion was evident if on any day the value of the fixed time effect was greater than a threshold based on conventional (99 percent) significance levels.

The advantages of the approach included that a long daily time-series of contagion measuring the statistical and economic (sign and magnitude) significance of contagion could be extracted providing a more detailed picture of contagion than commonly employed tests. This means that sample selection bias problems are avoided as unlike in most alternative models, identification does not depend on the ex post selection of the crisis period. Contagion is determined endogenously. Finally, although it is possible to detect the source country of contagion, it does not need to be chosen as part of the model identification process.

The results confirmed previous research on contagion in that common volatility arising during a crisis period primarily reflects interdependencies rather than contagion. Shocks due to contagion were relatively rare and short-lived, with only 28 days in four main periods detected. Contagion had both negative and positive affects on all asset markets simultaneously, but reversed quickly. The four main periods of contagion detected were: (i) September 2 to September 4, 1997, (ii) October 24 to October 30, 1997; (iii) December 12, 15 and 23, 1997 and (iv) January 8 to January 28, 1998 along with several dates in February, March and May of 1998. Events occurring on these dates were analysed, and it was found that Hong Kong was the main driver of system-wide contagion. Although Korea, Indonesia, and Thailand were also in the headlines at this time, they did not have an important role as Hong Kong for contagion. 


\section{References}

Allen, F. and Babus, A., 2008, "Networks in Finance”, Wharton Financial Institutions Working Paper \#08 7, University of Pennsylvania.

Ang, A. and Chen, J., 2002, “Asymmetric Correlations of Equity Portfolios”, Journal of Financial Economics, 63, 443-494.

Athukorala, P-C., 2001, Crisis and Recovery in Malaysia: The Role of Capital Controls, Edward Elgar Publishing Limited, UK.

Bae, K.H., Karolyi, G.A. and Stulz, R.M., 2003, “A New Approach to Measuring Financial Contagion”, Review of Financial Studies, 16, 717-763.

Baig, T. and Goldfajn, I., 1999, “Financial Market Contagion in the Asian Crisis”, IMF Staff Papers, 46, 167-195.

Baur, D. and Fry, R.A., 2006, "Endogenous Contagion: A Panel Data Analysis”, CAMA Working Paper, 9/2006.

Baur, D. and Schulze, N., 2005, “Coexceedances in Financial Markets - A Quantile Regression Analysis of Contagion”, Emerging Markets Review, 6, 21-43.

Bayoumi, T., Fazio, G., Kumar, M. and MacDonald, R., 2008, "Fatal Attraction: Using Distance to Measure Contagion in Good Times as Well as Bad”, Review of Financial Economics, 16, 259-273.

BBC, 1998, "Business: The Economy Meltdown in Asia - Part 4: Chronology of a Crisis”, http://news.bbc.co.uk/1/hi/business/the_economy/122546.stm.

Bekaert, G., Harvey, C.R. and Ng, A., 2005, “Market Integration and Contagion”, Journal of Business, 78, 39-70.

Boyer, B.H., Kumagai, T. and Yuan, K., 2006, "How Do Crises Spread? Evidence from Accessible and Inaccessible Stock Indices”, Journal of Finance, LXI, 957-1003.

Boyson, N.M., Stahel, C.W. and Stulz, R., 2008, “Hedge Fund Contagion and Liquidity”, Fisher College of Business Dice Center Working Paper 2008-08.

Butler, K.C and Joaquin, D.C., 2002, “Are the Gains from International Portfolio Diversification Exaggerated? The Influence of Downside Risk in Bear Markets”, Journal of International Money and Finance, 21, 981-1011.

Calvo, S. and Mendoza, E. 2000, "Rational Contagion and the Globalization of Securities Markets”, Journal of International Economics, 51, 79-113.

Calvo, S. and Reinhart, C., 1996, "Capital Flows to Latin America: Is there Evidence of Contagion Effects”, World Bank Policy Research Working Paper, No. 1619.

Corden, W. Max (2002), Too Sensational: On the Choice of Exchange Rate Regimes. Cambridge, Mass. and London, UK: MIT Press.

Corsetti, G., Pericoli, M. and Sbracia, M., 2001, “Correlation Analysis of Financial Contagion: What One Should Know Before Running a Test”, Economic Growth Centre Discussion Paper No. 822, Yale University. 
Corsetti, G., Pericoli, M. and Sbracia, M., 2005, "Some Contagion, Some Interdependence: More Pitfalls in Tests of Financial Contagion”, Journal of International Money and Finance, 24, 1177-1199.

Diebold, F.X and Yilmaz, K., 2008, "Measuring Financial Asset Return and Volatility Spillovers with Application to Global Equity Markets”, NBER Working Paper Number 13811.

Dungey, M., Fry, R.A., González-Hermosillo B. and Martin, V.L., 2005, "Empirical Modelling of Contagion: A Review of Methodologies”, Quantitative Finance, 75, 9-24.

Dungey, M., Fry, R.A. and Martin, V.L., 2003, "Equity Transmission Mechanisms from Asia to Australia: Interdependence or Contagion?”, Australian Journal of Management, 28, 157182.

Dungey, M. and Martin, V.L., 2004, "A Multifactor Model of Exchange Rates with Unanticipated Shocks: Measuring Contagion in the East Asian Currency Crisis”, Journal of Emerging Markets Finance, 3, 305-330.

Eichengreen, B., Rose, A.K. and Wyplosz, C., 1995, "Exchange Market Mayhem: The Antecedents and Aftermath of Speculative Attacks”, Economic Policy: A European Forum, 21, 249-296.

Eichengreen, B., Rose, A.K. and Wyplosz, C., 1996, "Contagious Currency Crises: First Tests”, Scandinavian Journal of Economics, 98, 463-484.

Favero, C.A. and Giavazzi, F., 2002, "Is the International Propagation of Financial Shocks Non-Linear? Evidence from the ERM”, Journal of International Economics, 57, 231-246.

Forbes, K. and Rigobon, R., 2002, "No Contagion, Only Interdependence: Measuring Stock Market Co-movements”, Journal of Finance, 57, 2223-2261.

Fratzscher, M., 1999, “What Causes Currency Crises: Sunspots, Contagion or Fundamentals?”, EUI Working Paper Eco No. 99/ 39.

Fratzscher, M., 2003, “On Currency Crises and Contagion”, International Journal of Finance and Economics, 8, 109-129.

Gai, P. and Kapadia, S., 2008, “Contagion in Financial Networks”, manuscript, Australian National University.

Ito, T., 2007, “Asian Currency Crisis and the International Monetary Fund, 10 Years Later: Overview”, Asian Economic Policy Review, 2, 16-49.

Jackson, M.O and Rogers, B. W., 2007, "Relating Network Structure to Diffusion Properties through Stochastic Dominance”, The BE Journal of Theoretical Economics Advances, 7, 1-13.

Kaminsky, G.L. and Schmukler, S.L., 1999,"What Triggers Market Jitters? A Chronicle of the Asian Crisis”, Journal of International Money and Finance, 18, 537-560.

Kaminsky, G.L. and Reinhart, C.M., 2000, “On Crises Contagion and Confusion”, Journal of International Economics, 51, 145-168.

Kodres, L.E. and Pritsker, M., 2002, "A Rational Expectations Model of Financial Contagion, Journal of Finance, 57, 768-799. 
Kyle, A.S. and Xiong, W., 2001, “Contagion as a Wealth Effect”, Journal of Finance, 56, 1410-1440.

Lo, A.C. and Mackinlay, A.W. 1990, "When are Contrarian Profits Due to Stock Market Overreaction?”, Review of Financial Studies, 3, 175-205.

Masson, P.R., 1999, “Contagion: Monsoonal Effects, Spillovers, and Jumps Between Multiple Equilibria”, in Agénor, P., Miller, M. and Vines, D. (eds), The Asian Crises: Causes, Contagion and Consequences, Cambridge: Cambridge University Press.

Mody, A. and Taylor, M., 2007, "Regional Vulnerability: The Case of Asia”, Journal of International Money and Finance, 26, 1292-1310.

Pesaran, H. and Pick, A., 2007, "Econometric Issues in the Analysis of Contagion”, Journal of Economic Dynamics and Control, 31, 1245-1277.

Pericoli, M. and Sbracia, M., 2003, “A Primer on Financial Contagion”, Journal of Economic Surveys, 17, 571-608.

Rigobon, R., 2003, "On the Measurement of the International Propagation of Shocks: Is the Transmission Stable?”, Journal of International Economics, 61, 261-283.

Van Rijckeghem, C. and Weder, B., 2003, "Spillovers through Banking Centres: A Panel Data Analysis of Bank Flows”, Journal of International Money and Finance, 22, 483-509.

Wongswan, J. 2003, “Contagion: An Empirical Test”, International Finance Discussion Paper no 775. Washington D.C., Board of the Governors of the Federal Reserve System.

Washington Post, 1998, “Asia's Financial Crisis 1997-1999” http://www.washingtonpost.com/wp-srv/business/longterm/asiaecon/timeline.htm

Yuan, K., 2005, “Asymmetric Price Movements and Borrowing Constraints: A Rational Expectations Equilibrium Model of Crises, Contagion, and Confusion”, Journal of Finance, 60, 379-411. 
Figure 1

Equity market indices (prices) for eleven Asian countries, April 1997-July 2003.
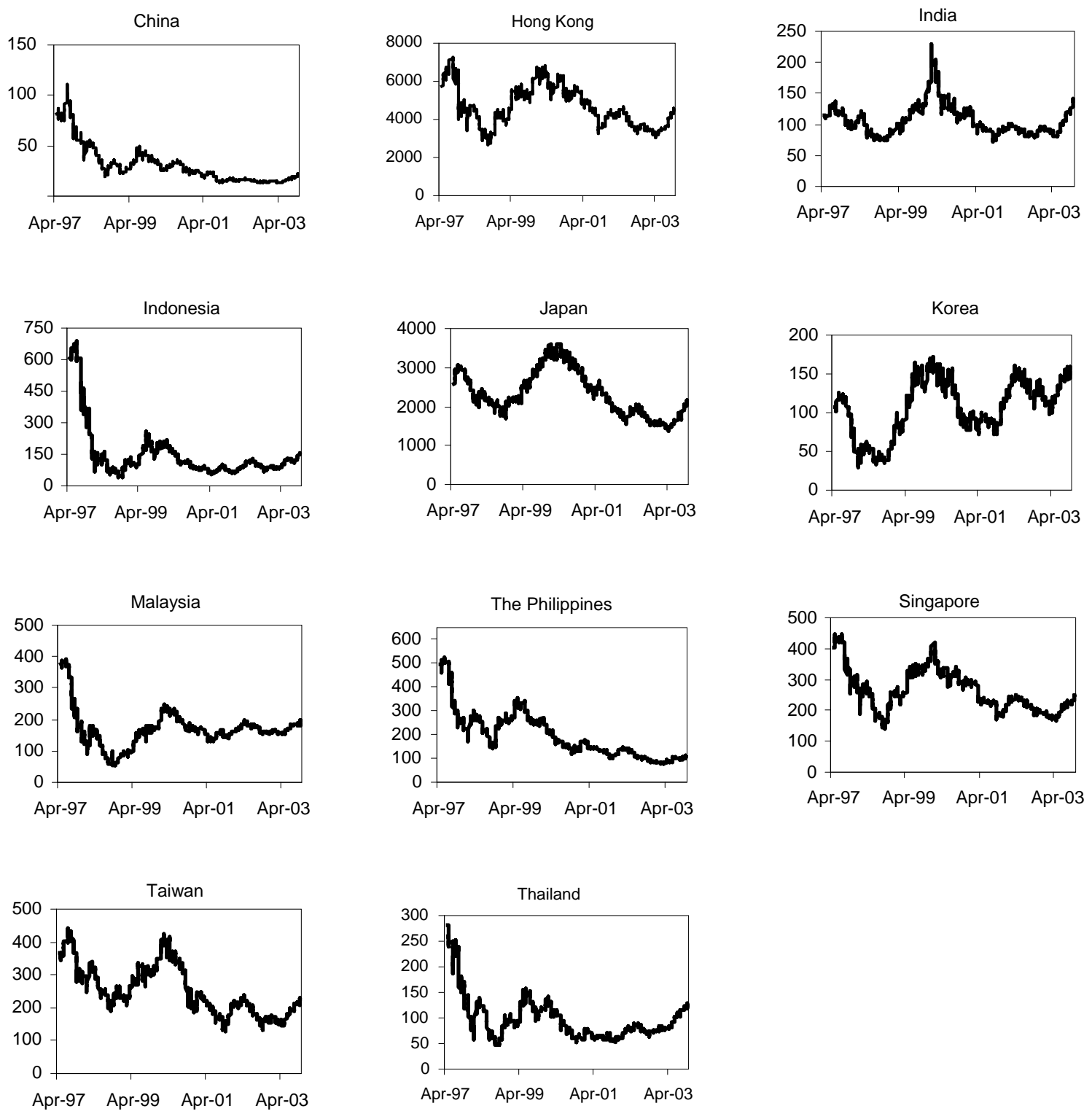
Figure 2

Equity market returns for eleven Asian countries, April 1997-July 2003.
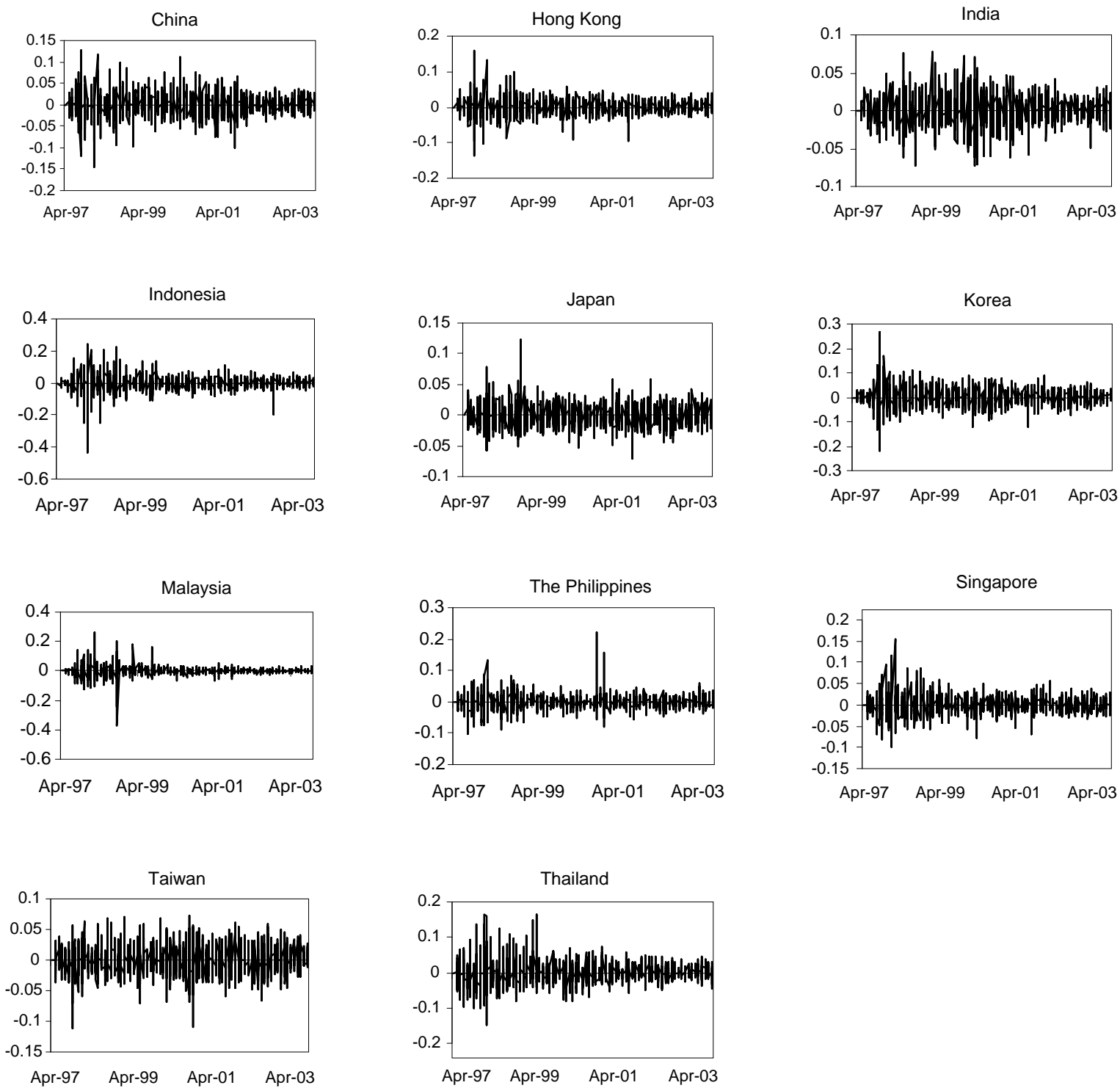


\section{Table 1}

Descriptive statistics of the continuously compounded equity index returns. Panel 1 presents the statistics calculated for the total sample period (April 30, 1997 to October 22, 2003). Panel 2 presents the statistics calculated for the period fixed time effects period (May 2, 1997 to May 29, 1998).

\begin{tabular}{|c|c|c|c|c|c|c|}
\hline Market & Mean & Std. Dev. & Minimum & Maximum & Skewness & Kurtosis \\
\hline \multicolumn{7}{|c|}{ Panel 1: total sample period } \\
\hline China & -0.0008 & 0.0235 & -0.1444 & 0.1274 & 0.0838 & 6.7425 \\
\hline Hong Kong & -0.0001 & 0.0195 & -0.1377 & 0.1601 & 0.1772 & 11.0052 \\
\hline India & 0.0001 & 0.0170 & -0.0732 & 0.0782 & -0.1901 & 5.3206 \\
\hline Indonesia & -0.0008 & 0.0392 & -0.4306 & 0.2381 & -0.9206 & 20.0683 \\
\hline Japan & -0.0001 & 0.0159 & -0.0716 & 0.1227 & 0.3765 & 6.0370 \\
\hline Korea & 0.0002 & 0.0322 & -0.2167 & 0.2688 & 0.3021 & 10.5934 \\
\hline Malaysia & -0.0004 & 0.0262 & -0.3695 & 0.2568 & -0.7011 & 43.1146 \\
\hline The Philippines & -0.0009 & 0.0203 & -0.1036 & 0.2197 & 1.2229 & 16.8339 \\
\hline Singapore & -0.0003 & 0.0186 & -0.1003 & 0.1552 & 0.4859 & 9.4968 \\
\hline Taiwan & -0.0003 & 0.0198 & -0.1113 & 0.0739 & 0.0389 & 4.9489 \\
\hline Thailand & -0.0005 & 0.0270 & -0.1489 & 0.1644 & 0.6949 & 8.3497 \\
\hline \multicolumn{7}{|c|}{ Panel 2: fixed time effects period } \\
\hline China & -0.0024 & 0.0308 & -0.1444 & 0.1274 & -0.1025 & 7.0513 \\
\hline Hong Kong & -0.0017 & 0.0282 & -0.1377 & 0.1601 & 0.3537 & 10.4881 \\
\hline India & -0.0005 & 0.0138 & -0.0434 & 0.0484 & -0.0881 & 3.8202 \\
\hline Indonesia & -0.0071 & 0.0680 & -0.4306 & 0.2381 & -1.0992 & 10.6949 \\
\hline Japan & -0.0008 & 0.0171 & -0.0579 & 0.0785 & 0.2776 & 5.1391 \\
\hline Korea & -0.0035 & 0.0498 & -0.2167 & 0.2688 & 0.5596 & 9.1116 \\
\hline Malaysia & -0.0041 & 0.0402 & -0.1262 & 0.2568 & 1.1889 & 10.2783 \\
\hline The Philippines & -0.0023 & 0.0278 & -0.1036 & 0.1320 & 0.3466 & 5.7616 \\
\hline Singapore & -0.0024 & 0.0265 & -0.1003 & 0.1552 & 0.8462 & 9.4739 \\
\hline Taiwan & -0.0012 & 0.0190 & -0.1113 & 0.0627 & -0.6947 & 7.4313 \\
\hline Thailand & -0.0044 & 0.0407 & -0.1489 & 0.1644 & 0.7216 & 5.7182 \\
\hline
\end{tabular}




\section{Table 2}

Unconditional correlations of the continuously compounded equity index returns. The upper triangle contains the correlations calculated over the total sample period (April 30, 1997 to October 22, 2003). The lower triangle matrix contains the correlations calculated over the fixed time effects sample period (May 2, 1997 to May 29, 1998).

\begin{tabular}{|c|c|c|c|c|c|c|c|c|c|c|c|}
\hline Market & Chin & H.K. & India & Indon. & Japan & Korea & Malay. & Philip. & Sing. & Taiw. & Thai. \\
\hline China & 1.00 & 0.62 & 0.19 & 0.26 & 0.29 & 0.27 & 0.27 & 0.29 & 0.44 & 0.27 & 0.32 \\
\hline Hong Kong & 0.69 & 1.00 & 0.22 & 0.34 & 0.35 & 0.32 & 0.31 & 0.34 & 0.60 & 0.29 & 0.38 \\
\hline India & 0.17 & 0.24 & 1.00 & 0.11 & 0.16 & 0.21 & 0.12 & 0.13 & 0.20 & 0.14 & 0.18 \\
\hline Indonesia & 0.34 & 0.41 & 0.13 & 1.00 & 0.20 & 0.17 & 0.33 & 0.35 & 0.43 & 0.18 & 0.37 \\
\hline Japan & 0.24 & 0.34 & 0.07 & 0.19 & 1.00 & 0.28 & 0.22 & 0.21 & 0.38 & 0.24 & 0.26 \\
\hline Korea & 0.06 & 0.08 & 0.14 & 0.11 & 0.11 & 1.00 & 0.20 & 0.21 & 0.30 & 0.27 & 0.32 \\
\hline Malaysia & 0.32 & 0.38 & 0.16 & 0.50 & 0.23 & 0.21 & 1.00 & 0.25 & 0.39 & 0.18 & 0.36 \\
\hline Philippines & 0.38 & 0.45 & 0.16 & 0.46 & 0.17 & 0.14 & 0.45 & 1.00 & 0.41 & 0.17 & 0.38 \\
\hline Singapore & 0.54 & 0.67 & 0.21 & 0.58 & 0.33 & 0.06 & 0.60 & 0.62 & 1.00 & 0.32 & 0.46 \\
\hline Taiwan & 0.33 & 0.33 & 0.08 & 0.25 & 0.23 & 0.08 & 0.32 & 0.28 & 0.38 & 1.00 & 0.25 \\
\hline Thailand & 0.28 & 0.32 & 0.22 & 0.40 & 0.19 & 0.22 & 0.48 & 0.45 & 0.47 & 0.31 & 1.00 \\
\hline
\end{tabular}


Table 3

Parameter estimates and z-statistics of the regional and global factors from equation (1).

\begin{tabular}{|c|c|c|c|c|}
\hline \multirow[b]{2}{*}{ Market } & \multicolumn{4}{|c|}{ Parameter estimates } \\
\hline & Regional factor $\beta_{i l}$ & z-statistics & Global factor $\beta_{i 2}$ & z-statistics \\
\hline China & 0.71 & 28.09 & 0.09 & 2.87 \\
\hline Hong Kong & 0.58 & 32.23 & 0.22 & 8.45 \\
\hline India & 0.42 & 22.27 & 0.05 & 1.67 \\
\hline Indonesia & 0.63 & 18.70 & 0.05 & 1.37 \\
\hline Japan & 0.34 & 17.38 & 0.34 & 11.45 \\
\hline Korea & 1.48 & 83.28 & 0.00 & 0.04 \\
\hline Malaysia & 0.36 & 20.57 & -0.07 & -2.95 \\
\hline The Philippines & 0.43 & 16.43 & 0.00 & 0.06 \\
\hline Singapore & 0.56 & 29.00 & 0.24 & 8.56 \\
\hline Taiwan & 0.87 & 45.22 & -0.03 & -0.88 \\
\hline Thailand & 0.74 & 27.73 & 0.04 & 0.93 \\
\hline
\end{tabular}




\section{Figure 3}

Coefficient estimates and z-statistics of the fixed time effects. The fixed time effects sample period is from May 2, 1997 to May 29, 1998. The dashed lines in b) indicate the 99 percent confidence level.

a) Fixed time effects

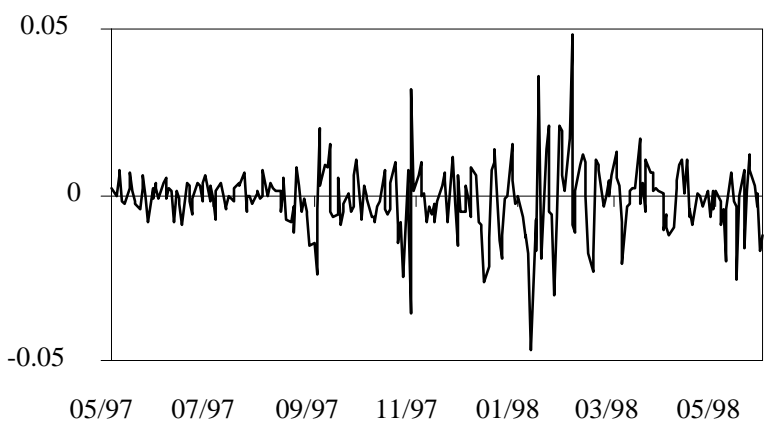

b) z-statistics

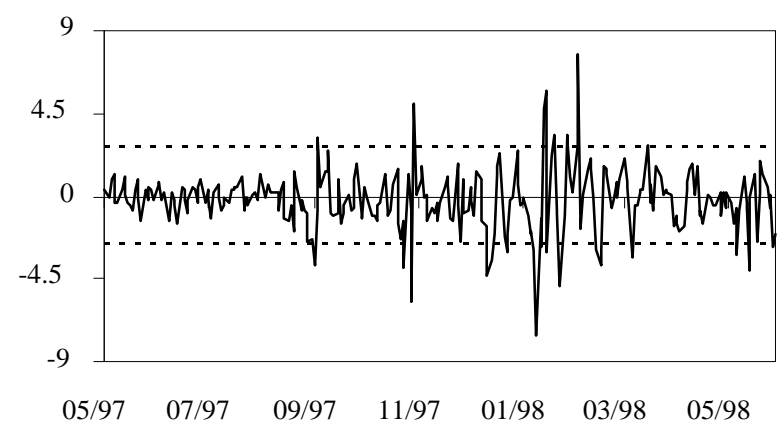


Table 4

Evidence of contagion for different specifications.

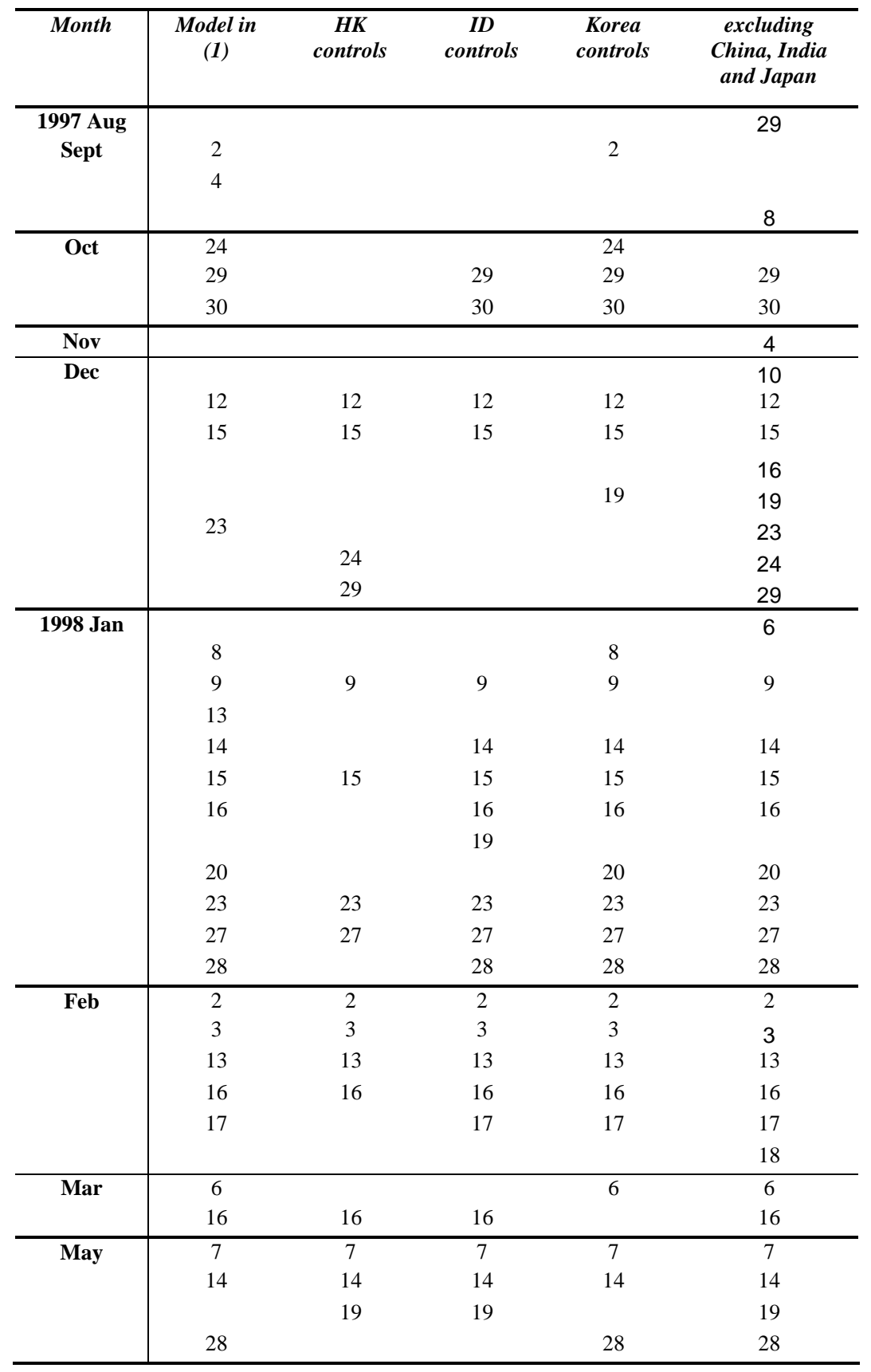




\section{Table 5}

Evidence of asymmetries during the fixed time effects sample period (May 2, 1997 to May 29, 1998).

\begin{tabular}{lcccc}
\hline & Fixed time effect period & & Days when contagion is evident \\
\cline { 2 - 4 } & Mean & No. of observations & Mean & No. of observations \\
\cline { 3 - 4 } All observations & $-0.11 \%$ & 281 & $-0.59 \%$ & 28 \\
Positive observations & $0.67 \%$ & 125 & $2.60 \%$ & 10 \\
Negative observations & $-0.74 \%$ & 156 & $-2.36 \%$ & $-0.59 \%$ \\
\hline
\end{tabular}




\section{Figure 4}

Coefficient estimates and z-statistics of the fixed time effects for the model controlling for respectively, Hong Kong (HK), Indonesia (ID) and Korea (KR). The fixed time effects sample period is from May 2, 1997 to May 29, 1998. The dashed lines in the second column of the figures indicates the 99 percent confidence level.

a) Fixed time effects - HK controls

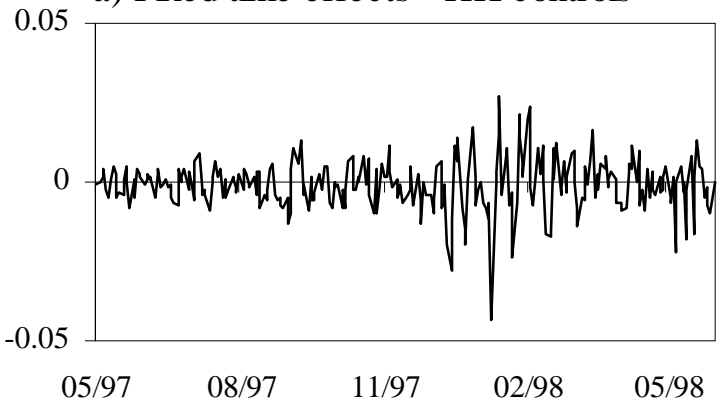

c) Fixed time effects - ID controls

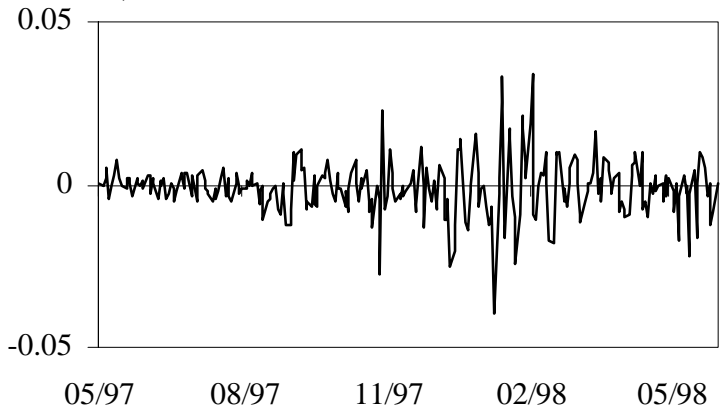

e) Fixed time effects - KR controls

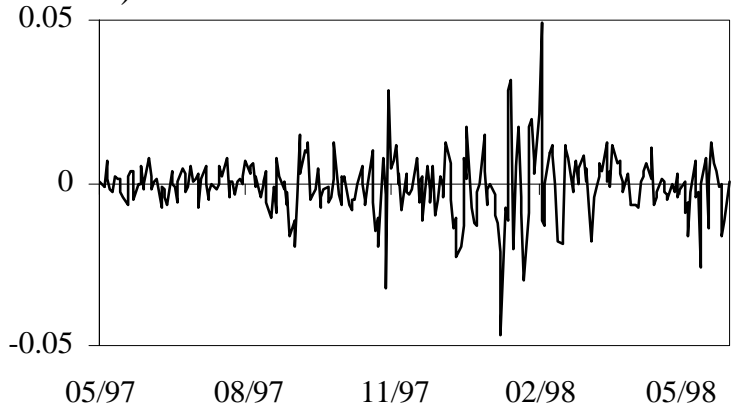

b) z-statistics - HK controls

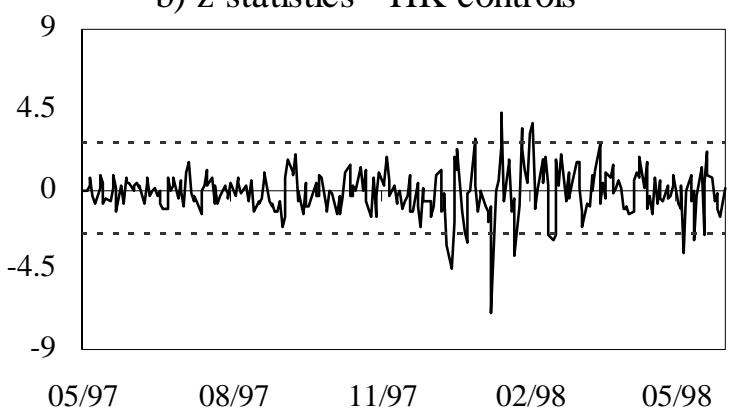

d) z-statistics - ID controls

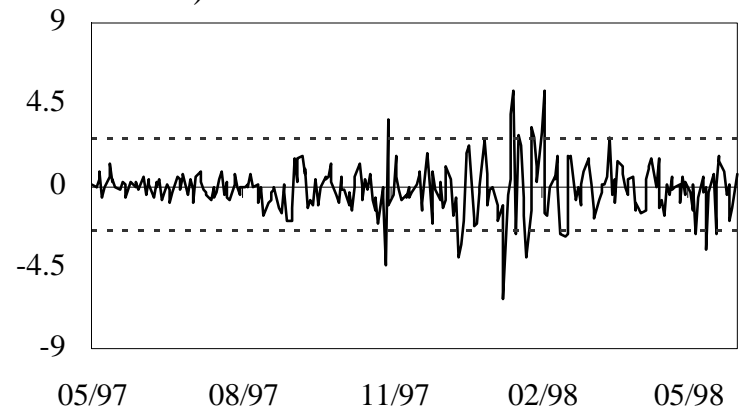

f) z-statistics - KR controls

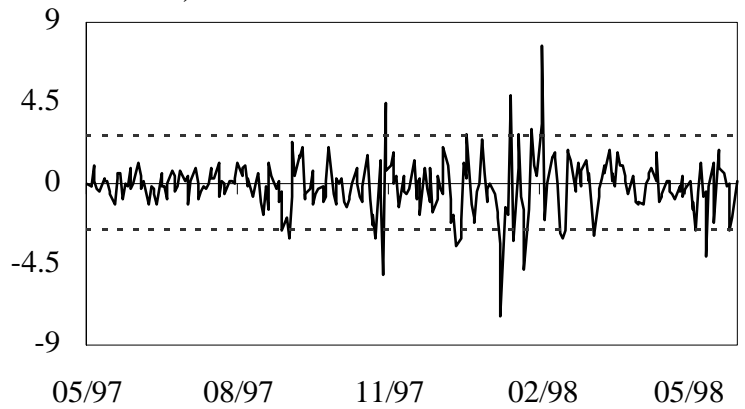




\section{Figure 5}

Coefficient estimates and z-statistics of the fixed time effects for alternative fundamentals assumptions. The fixed time effects (FTE) sample period is from May 2, 1997 to May 29, 1998. The dashed lines in the second column of the figures indicates the 99 percent confidence level.

a) Fixed time effects -VAR residuals

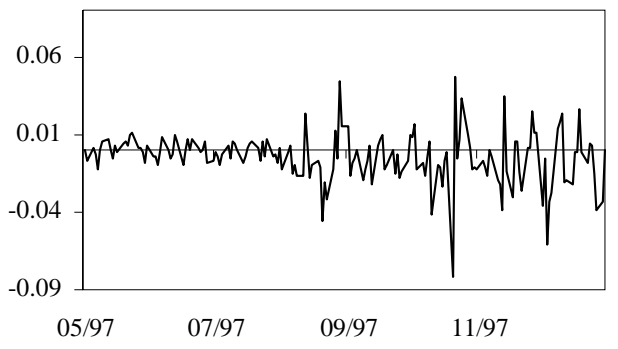

c) Fixed time effects - global factor only

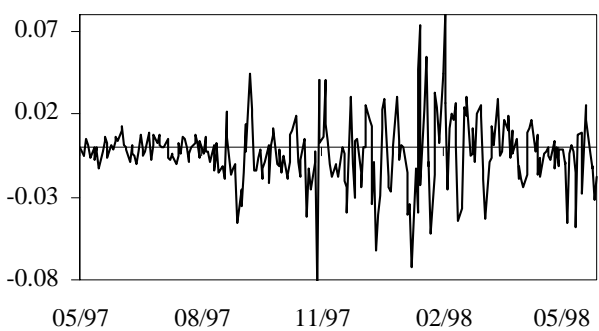

e) FTE - regional factor only

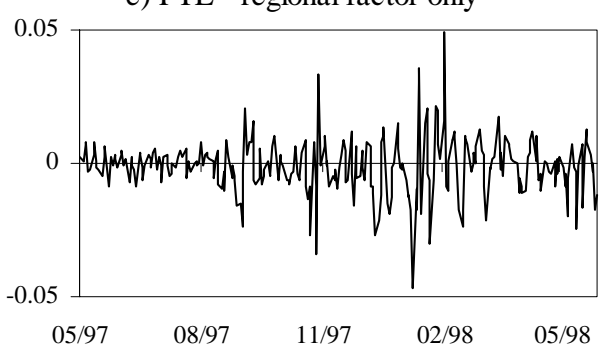

g) FTE - no China, India or Japan

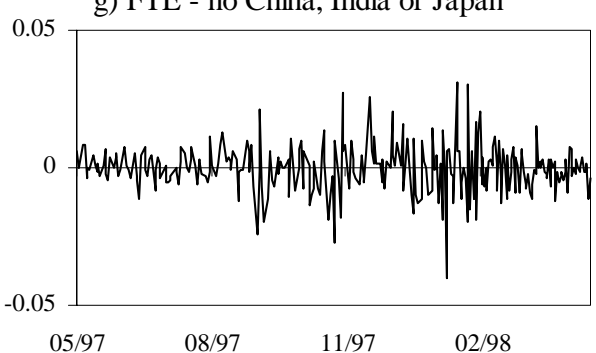

b) z-statistics - VAR residuals

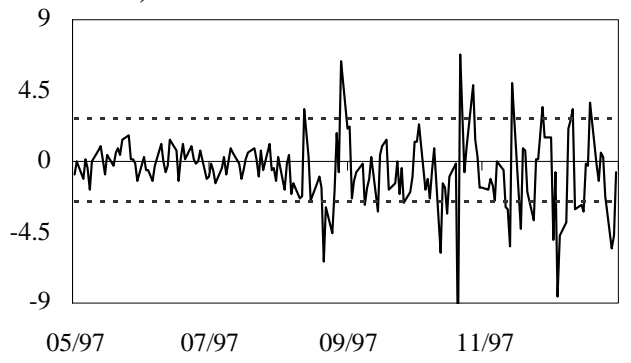

d) z-statistics - global factor only

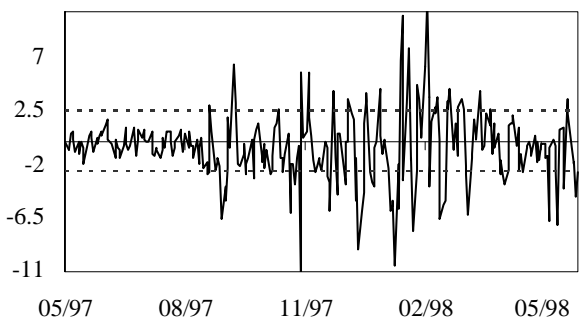

f) z-statistics - regional factor only

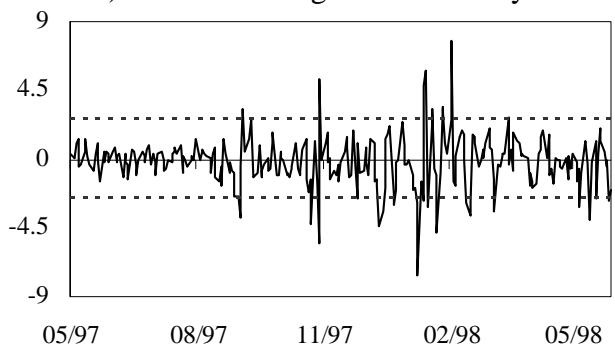

h) z-statistics - no China, India or Japan

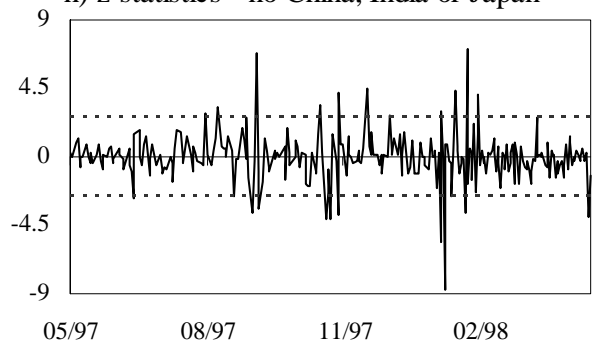


